\title{
A NOVEL CONFIGURATION OF TWO-WHEELED SELF-BALANCING ROBOT
}

\author{
Qingwen Qian, Junfeng Wu, Zhe Wang
}

Original scientific paper

A novel design of the two-wheeled self-balancing robot (TWSR) was presented in this research. The robot was called two-wheeled self-balancing vehiclependulum system (TWSVPS). Compared with TWSR, the TWSVPS has a single pendulum (SP), which was passively jointed to the robot body through the $\mathrm{O}_{1}$ axis. The difficulty and complexity of control and modelling were increased due to the additional degree of freedom (DOF) which was offered by the SP rotated around the $\mathrm{O}_{1}$ axis. To simplify the analysis, the TWSVPS can be considered to be the mobile double inverted pendulum. Lagrangian dynamic formulation is used to derive the system dynamics due to its relative simplicity. The parallel double fuzzy controller based on information fusion technology was designed and simulated in MATLAB. The results show that the method is feasible and TWSVPS has excellent moving stability. The new developed configuration is of great importance in various applications including self-balance robots, wheelchairs on two wheels, stability analysis of multi links system etc.

Keywords: double inverted pendulum; fuzzy optimal control; information fusion; Lagrangian formulation; two wheeled self-balancing vehicle-pendulum system

\section{Nova konfiguracija samobalansirajućeg robota na dva kotača}

Izvorni znastveni članak U ovom se istraživanju predstavlja novi projekt samobalansirajućeg robota na dva kotača - two wheeled self-balancing robot (TWSR). Robot je nazvan two-wheeled self-balancing vehicle-pendulum system (TWSVPS). U usporedbi s TWSR, TWSVPS ima jedno klatno (single pendulum (SP)) koje je pasivno spojeno s tijelom robota preko $\mathrm{O}_{1}$ osovine. Teškoća i složenost upravljanja te modeliranje povećani su zbog dodatnog stupnja slobode - degree of freedom (DOF) s klatnom koje rotira oko osovine $\mathrm{O}_{1}$. Zbog jednostavnije analize, TWSVPS se može smatrati vozilom s pokretnim dvostruko obrnutim klatnom. Zbog svoje relativne jednostavnosti, za izvođenje dinamike sustava primijenjena je Lagrangeova dinamička formulacija. Paralelni dvostruki fuzzy upravljač zasnovan na informacijskoj tehnologiji fuzije projektiran je i simuliran u MATLAB-u. Rezultati pokazuju da je metoda izvediva i TWSVPS je izvanredno stabilan u kretanju. Novo razvijena konfiguracija je od velike važnosti u raznim primjenama uključujući samo-balansirajuće robote, kolica za bolesnike na dva kotača, analizu stabilnosti višezglobnih sustava itd.

Ključneriječi: dvostruko obrnuto klatno; fuzzy optimalno upravljanje; informacijska fuzija; Lagrangeova formulacija; sustav samobalansirajućeg vozila na dva kotača s klatnom

\section{Introduction}

The TWSR system is favoured by most researchers due to its highly nonlinear, strong coupling and unstable system [1] and is also studied in detail on the modelling and control strategy. Nguyen Gia Minh Thao et al. [2] used the Newton's Second Law of motion to identify the mathematical model of robot and PID control algorithm. Yufeng Zhuang et al. [3] derived the system dynamics by Lagrangian formulation. Mohammad Mahdi Azimi et al. [4] used Deterministic Autoregressive Moving Average model and robust control. Some new configurations have expanded the applications of TWSR systems by adding more DOF to the system. K. Goher et al. $[5,6]$ designed a new configuration of two-wheeled vehicles based on multiple link inverted pendulum systems with multiple DOF. A. Almeshal et al. [7] designed a new configuration of a two-wheeled double inverted pendulum-like robotic vehicle with movable payload on an inclined plane. These new configurations consisted of TWSR and single pendulum (SP), but TWSR and SP were jointed through the motor. The authors have presented successful TWSVPS which have TWSR and SP, the novel point is that the TWSR body and SP were passively jointed through $\mathrm{O} 1$ axis.

The TWSR was controlled by using many algorithms such as a modular fuzzy control approach for twowheeled wheelchair [8] and robust control of selfbalancing two-wheeled robot [9]. The parallel double fuzzy controller is developed to stabilize the TWSVPS in this research. Information fusion was used to avoid the fuzzy rule explosion, because TWSVPS had multiple input and output. The fuzzy variables of input were gained by combining the fuzzy control theory with the optimal control theory.

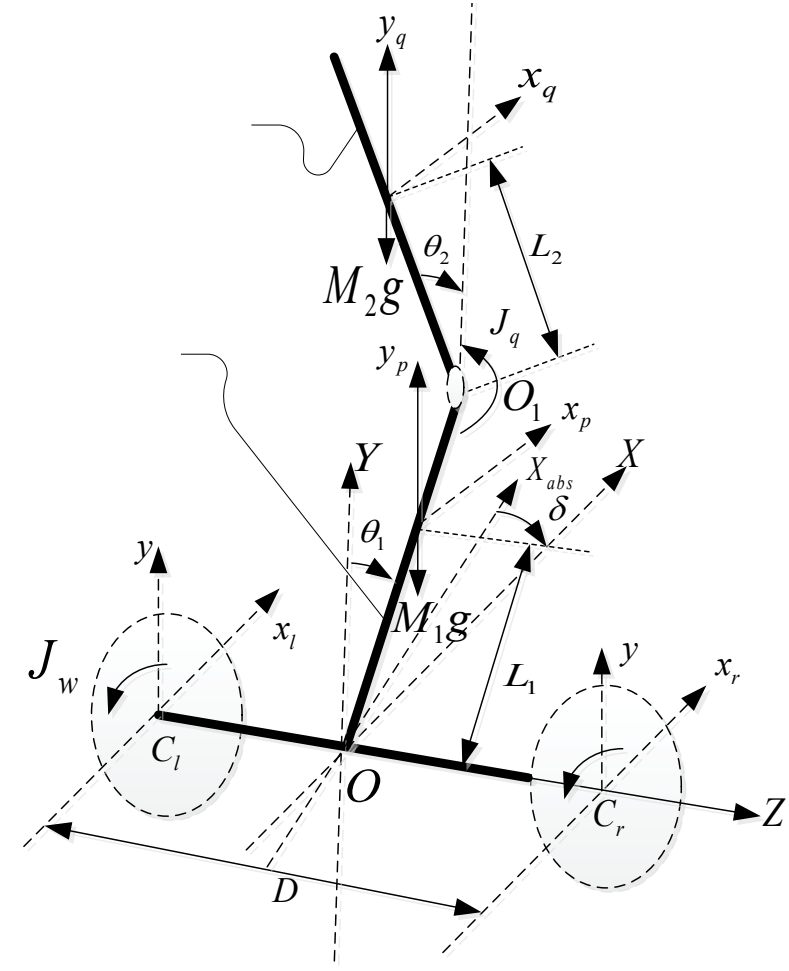

Figure 1 The dynamics mechanics diagram of a novel self-balancing robot 


\section{Dynamics model of robot 2.1 System description}

The TWSVPS is composed of SP, robot body and two wheels, shown in Fig. 1. The SP and robot body are passively jointed through the $\mathrm{O}_{1}$ axis. The SP can translate along with TWSR and rotate around the $\mathrm{O}_{1}$ axis. Two wheels are jointed to the two motors which have been installed on the robot body. The robot body can translate along with the robot and rotate around the $Z$ axis.
TWSVPS can rotate around the $Y$ axis. TWSVPS is driven by two direct motors, which help the system to be stabilized at the upright position or at any angular position as required by the system control strategy. There are three encoders in the whole robot. One is installed on $\mathrm{O}_{1}$ axis to measure the angle between SP and $Y$ axis; the other two are installed on the output shaft of two motors respectively.

The parameters and description are shown in Tab. 1.

Table 1 The variables and parameters of TWSVPS

\begin{tabular}{|c|c|c|c|}
\hline Parameter & Description & Values & Units \\
\hline$R$ & Radius of wheel & 0,106 & $\mathrm{~m}$ \\
\hline$M_{w}$ & Mass of wheel & 0,42 & $\mathrm{~kg}$ \\
\hline$D$ & Distance between wheels along $Z$ axis & 0,44 & $\mathrm{~m}$ \\
\hline$M_{1}$ & Mass of self-balancing robot body & 21 & $\mathrm{~kg}$ \\
\hline$L_{1}$ & Distance of robot body center of mass to $Z$ axis & 0,3 & $\mathrm{~m}$ \\
\hline$M_{2}$ & Mass of rod & 3 & $\mathrm{~kg}$ \\
\hline$L_{2}$ & Distance of rod center of mass to passive joint & 0,5 & $\mathrm{~m}$ \\
\hline$\theta_{1}$ & Angle position of robot body to the positive $Y$ axis & & ○ \\
\hline$\theta_{2}$ & Angle position of single pendulum to the positive $Y$ axis & & $\circ$ \\
\hline$J_{w}$ & The moment of inertia of the wheel around $Z$ axis & & $\mathrm{kg} \cdot \mathrm{m}^{2}$ \\
\hline$J_{\delta 2}$ & The moment of inertia of the robot body around $Y$ axis & & $\mathrm{kg} \cdot \mathrm{m}^{2}$ \\
\hline$J_{P}$ & The moment of inertia of the robot body around $Z$ axis & & $\mathrm{kg} \cdot \mathrm{m}^{2}$ \\
\hline$J_{\delta 1}$ & The moment of inertia of the rod around $Y$ axis & & $\mathrm{kg} \cdot \mathrm{m}^{2}$ \\
\hline$J_{q}$ & The moment of inertia of the rod around $Z$ axis & & $\mathrm{kg} \cdot \mathrm{m}^{2}$ \\
\hline$\theta_{l}$ & Angle of rotations at the left wheel & & $\circ$ \\
\hline$\theta_{r}$ & Angle of rotations at the right wheel & & $\circ$ \\
\hline$C_{l}$ & Input torque of left wheel & & $\mathrm{N} \cdot \mathrm{m}$ \\
\hline$C_{r}$ & Input torque of right wheel & & $\mathrm{N} \cdot \mathrm{m}$ \\
\hline$\delta$ & Angle between robot body and $X$ axis & & o \\
\hline$x$ & Displacement of robot & & $\mathrm{m}$ \\
\hline$T_{1}$ & Kinetic energy of translation of wheels & & $\mathrm{J}$ \\
\hline$T_{2}$ & Kinetic energy of rotation of wheels & & $\mathrm{J}$ \\
\hline$T_{3}$ & Kinetic energy of translation of robot body & & $\mathrm{J}$ \\
\hline$T_{4}$ & Kinetic energy of rotation of robot body around $Z$ axis & & $\mathrm{J}$ \\
\hline$T_{5}$ & Kinetic energy of rotation of robot body around $Y$ axis & & $\mathrm{J}$ \\
\hline$T_{6}$ & Kinetic energy of translation of rod & & $\mathrm{J}$ \\
\hline$T_{7}$ & Kinetic energy of translation of rod around O' axis & & $\mathrm{J}$ \\
\hline$T_{8}$ & Kinetic energy of rotation of rod around $Y$ axis & & $\mathrm{J}$ \\
\hline$T$ & The total kinetic energy of system & & $\mathrm{J}$ \\
\hline$V_{1}$ & Potential energy of robot body & & $\mathrm{J}$ \\
\hline$V_{2}$ & Potential energy of rod & & $\mathrm{J}$ \\
\hline$V$ & The total potential energy of system & & $\mathrm{J}$ \\
\hline$U$ & The total energy of system & & $\mathrm{J}$ \\
\hline
\end{tabular}

\subsection{System description}

Because the robot is a complex nonlinear system, in order to simplify the analysis in the process of dynamic modelling, the following assumptions were put forward in this paper. All parts of the robot are rigid body, and ignore the interference force from outside and the friction between the robot body and two wheel axles. There is no relative sliding between two wheels with the ground. The system kinetic energy can be expressed as:

$$
\begin{aligned}
& T=T_{1}+T_{2}+T_{3}+T_{4}+T_{5}+T_{6}+T_{7}+T_{8} \\
& T_{1}=\frac{1}{2} M_{w} R^{2}\left(\dot{\theta}_{l}^{2}+\dot{\theta}_{r}^{2}\right) \\
& T_{2}=\frac{1}{2} J_{w}\left(\dot{\theta}_{l}^{2}+\dot{\theta}_{r}^{2}\right)
\end{aligned}
$$

$$
\begin{aligned}
& T_{3}=\frac{1}{2} M_{1}\left[\left(\frac{R}{2}\left(\dot{\theta}_{l}+\dot{\theta}_{r}\right)+\dot{\theta}_{1} L_{1} \cos \theta_{1}\right)^{2}+\left(\dot{\theta}_{1} L_{1} \sin \theta_{1}\right)^{2}\right] \\
& T_{4}=\frac{1}{2} J_{p} \dot{\theta}_{1}^{2} \\
& T_{5}=\frac{1}{2} J_{\sigma 1} \dot{\sigma}^{2} \\
& T_{6}=\frac{1}{2} M_{2}\left[\left(\frac{R}{2}\left(\dot{\theta}_{l}+\dot{\theta}_{r}\right)+2 L_{1} \dot{\theta}_{1} \cos \theta_{1}+L_{2} \dot{\theta}_{2} \cos \theta_{2}\right)^{2}+\right. \\
& \left.+\left(2 L_{1} \dot{\theta}_{1} \cos \theta_{1}+L_{2} \dot{\theta}_{2} \cos \theta_{2}\right)^{2}\right] \\
& T_{7}=\frac{1}{2} J_{q} \dot{\theta}_{2}^{2} \\
& T_{8}=\frac{1}{2} J_{\sigma_{2}} \dot{\sigma}^{2}
\end{aligned}
$$


Since there is no motions for the robot in the $Y$ direction as the wheels remain in full contact with the ground, there is no potential energy for the robot in the $Y$ direction. The system potential energy can be expressed as $V=V_{1}+V_{2}$.

$$
\begin{aligned}
& V_{1}=M_{1} g L_{1} \cos \theta_{1} \\
& V_{2}=M_{2} g\left(2 L_{1} \cos \theta_{1}+L_{2} \cos \theta_{2}\right)
\end{aligned}
$$

\subsection{Lagrangian modelling}

The mathematical model can be established through lots of methods. Generally, the Newton-Euler formulation and Lagrangian equation can be used in the model establishing. There are several reasons for selecting Lagrangian approach in this research. First, the derivation is based on energy calculations of the physical system. As energy calculations are independent of vectors representation, the derivation is simple compared to Newton-Euler formulation.

Second, it is simple and more natural to describe the system DOF by using generalized coordinates. Additionally another advantage of Lagrange's dynamic is the method of Lagrangian multipliers which can also be used when you do not know the nature of some force during constrained motion. Lagrangian Dynamics is derived from Newton's Laws and has the same restrictions as those laws naturally. The Lagrangian equation of the robot can be described as follows:

$$
\begin{aligned}
& \frac{\partial}{\mathrm{d} t}\left(\frac{\partial L}{\partial \dot{\theta}_{l}}\right)-\frac{\partial L}{\partial \theta_{l}}=C_{l} \\
& \frac{\partial}{\mathrm{d} t}\left(\frac{\partial L}{\partial \dot{\theta}_{r}}\right)-\frac{\partial L}{\partial \theta_{r}}=C_{r} \\
& \frac{\partial}{\mathrm{d} t}\left(\frac{\partial L}{\partial \dot{\theta}_{1}}\right)-\frac{\partial L}{\partial \theta_{1}}=0 \\
& \frac{\partial}{\mathrm{d} t}\left(\frac{\partial L}{\partial \dot{\theta}_{2}}\right)-\frac{\partial L}{\partial \theta_{2}}=0
\end{aligned}
$$

where: $L=T-V$ - Lagrangian function, $T$ - system kinetic energy, $V$ - system potential energy.

Substituting the parameters in Eqs. (11) $\div$ (14) and calculated, the dynamic equations of robot system can be described as follows:

$$
\begin{aligned}
& \frac{1}{4} R^{2}\left(M_{1}+M_{2}\right)\left(\ddot{\theta}_{l}+\ddot{\theta}_{r}\right)+\left(M_{w} R^{2}+J_{w}\right) \ddot{\theta}_{l}+R L_{1}\left(\frac{1}{2} M_{1}+M_{2}\right)\left(\ddot{\theta}_{1} \cos \theta_{1}-\dot{\theta}_{1}^{2} \sin \theta_{1}\right)+\frac{1}{2} M_{2} R L_{2}\left(\ddot{\theta}_{2} \cos \theta_{2}-\dot{\theta}_{2}^{2} \sin \theta_{2}\right)=C_{l} \\
& \frac{1}{4} R^{2}\left(M_{1}+M_{2}\right)\left(\ddot{\theta}_{l}+\ddot{\theta}_{r}\right)+\left(M_{w} R^{2}+J_{w}\right) \cdot \ddot{\theta}_{r}+R L_{1}\left(\frac{1}{2} M_{1}+M_{2}\right)\left(\ddot{\theta}_{1} \cos \theta_{1}-\dot{\theta}_{1}^{2} \sin \theta_{1}\right)+\frac{1}{2} M_{2} R L_{2}\left(\ddot{\theta}_{2} \cos \theta_{2}-\dot{\theta}_{2}^{2} \sin \theta_{2}\right)=C_{r}(1) \\
& R L_{1} \cos \theta_{1}\left(M_{1}+M_{2}\right)\left(\ddot{\theta}_{l}+\ddot{\theta}_{r}\right)-\frac{1}{2} M_{1} R L_{1} \dot{\theta}_{1} \sin \theta_{1}\left(\dot{\theta}_{l}+\dot{\theta}_{r}\right)+\left(4 M_{2} L_{1}^{2}+J_{p}+M_{1} L_{1}^{2} \cos ^{2} \theta_{1}\right) \ddot{\theta}_{1}+2 M_{2} L_{1} L_{2} \ddot{\theta}_{2} \cos \theta_{1} \cos \theta_{2}- \\
& -M_{1} L_{1}^{2} \dot{\theta}_{1}^{2} \sin \theta_{1} \cos \theta_{1}-2 M_{2} L_{1} L_{2} \dot{\theta}_{2}^{2} \sin \theta_{2} \cos \theta_{1}-\left(M_{1}+M_{2}\right) g L_{1} \sin \theta_{1}=0 \\
& \frac{1}{2} M_{2} R L_{2} \cos \theta_{2}\left(\ddot{\theta}_{l}+\ddot{\theta}_{r}\right)+2 M_{2} L_{1} L_{2} \ddot{\theta}_{1} \cos \theta_{1} \cos \theta_{1}+\left(M_{2} L_{2}^{2}+J_{q}\right) \ddot{\theta}_{2}-2 M_{2} L_{1} L_{2} \dot{\theta}_{1}^{2} \sin \theta_{1} \cos \theta_{2}-M_{2} g L_{2} \sin \theta_{2}=0
\end{aligned}
$$

Nearby the upright equilibrium, $\theta_{1} \approx 0, \theta_{2} \approx 0$, so the nonlinear mathematical model can be seen as linear. Supposed $\sin \theta_{1} \approx \theta_{1}, \sin \theta_{2} \approx \theta_{2}, \cos \theta_{1} \approx \theta_{1}, \cos \theta_{2} \approx \theta_{2}$, $\dot{\theta}_{1}^{2} \approx 0, \dot{\theta}_{2}^{2} \approx 0$. Finally the dynamic equations of the robot system can be described as follows:

$$
\begin{aligned}
& {\left[\frac{1}{2} R \cdot\left(M_{1}+M_{2}\right)+\frac{M_{w} R^{2}+J_{w}}{R}\right] \cdot \ddot{x}+\frac{D \cdot\left(M_{w} R^{2}+J_{w}\right)}{2 R} \cdot \ddot{\delta}+\frac{1}{2} R L_{1}\left(M_{1}+M_{2}\right) \cdot \ddot{\theta}_{1}+\frac{1}{2} M_{2} R L_{2} \ddot{\theta}_{2}=C_{l}} \\
& {\left[\frac{1}{2} R \cdot\left(M_{1}+M_{2}\right)+\frac{M_{w} R^{2}+J_{w}}{R}\right] \cdot \ddot{x}-\frac{D \cdot\left(M_{w} R^{2}+J_{w}\right)}{2 R} \cdot \ddot{\delta}+\frac{1}{2} R L_{1}\left(M_{1}+M_{2}\right) \cdot \ddot{\theta}_{1}+\frac{1}{2} M_{2} R L_{2} \ddot{\theta}_{2}=C_{r}} \\
& 2 L_{1}\left(M_{1}+M_{2}\right) \cdot \ddot{x}+\left(4 M_{2} L_{1}^{2}+J_{p}+M_{1} L_{1}^{2}\right) \cdot \ddot{\theta}_{1}+2 M_{2} L_{1} L_{2} \ddot{\theta}_{2}-\left(M_{1}+2 M_{2}\right) \cdot g L_{1} \theta_{1}=0
\end{aligned}
$$

$$
M_{2} L_{2} \ddot{x}+2 M_{2} L_{1} L_{2} \ddot{\theta}_{1}+\left(M_{2} L_{2}^{2}+J_{q}\right) \ddot{\theta}_{2}-M_{2} g L_{2} \theta_{2}=0
$$

$\left[x, \dot{x}, \theta_{1}, \dot{\theta}_{1}, \theta_{2}, \dot{\theta}_{2}, \delta, \dot{\delta}\right]^{\mathrm{T}}$ can be used as state variables of linear state space equation, the system state-space equations can be written in matrix form as (23):

$\left[\begin{array}{c}\dot{x} \\ \ddot{x} \\ \dot{\theta}_{1} \\ \ddot{\theta}_{1} \\ \dot{\theta}_{2} \\ \ddot{\theta}_{2} \\ \dot{\delta} \\ \ddot{\delta}\end{array}\right]=\left[\begin{array}{cccccccc}0 & 1 & 0 & 0 & 0 & 0 & 0 & 0 \\ 0 & 0 & a_{23} & 0 & a_{25} & 0 & 0 & 0 \\ 0 & 0 & 0 & 1 & 0 & 0 & 0 & 0 \\ 0 & 0 & a_{43} & 0 & a_{45} & 0 & 0 & 0 \\ 0 & 0 & 0 & 0 & 0 & 1 & 0 & 0 \\ 0 & 0 & a_{63} & 0 & a_{65} & 0 & 0 & 0 \\ 0 & 0 & 0 & 0 & 0 & 0 & 0 & 1 \\ 0 & 0 & 0 & 0 & 0 & 0 & 0 & 0\end{array}\right]\left[\begin{array}{c}x \\ \dot{x} \\ \theta_{1} \\ \dot{\theta}_{1} \\ \theta_{2} \\ \dot{\theta}_{2} \\ \delta \\ \dot{\delta}\end{array}\right]+\left[\begin{array}{cc}0 & 0 \\ b_{21} & b_{22} \\ 0 & 0 \\ b_{41} & b_{42} \\ 0 & 0 \\ b_{61} & b_{62} \\ 0 & 0 \\ b_{81} & b_{82}\end{array}\right]\left[\begin{array}{c}C_{1} \\ C_{r}\end{array}\right]$

Substituting all parameters into matrix (23) and decoupling, the system state-space equations can be written in matrix form as (24). The whole system can be 
controlled and observed through the analysis of the coefficient matrix by using MATLAB.

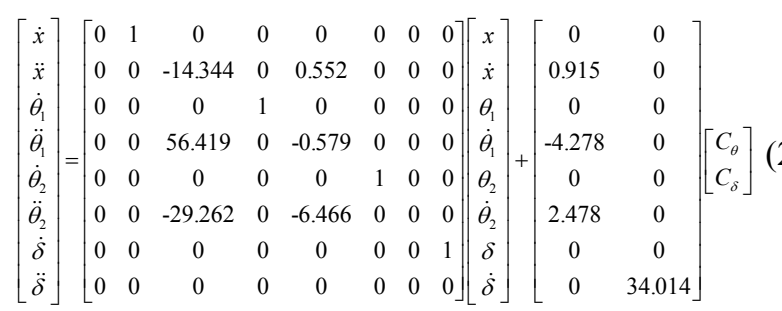

where $C_{\theta}$ was the coupling of $C_{\theta_{1}}$ and $C_{\theta_{2}}$.

According to (24), the balance and deflection subsystem model can be represented as (25) and (26) respectively:

$\dot{x}_{1}=A_{1} x_{1}+B_{1} u_{1}$

$A_{1}=\left[\begin{array}{cccccc}0 & 1 & 0 & 0 & 0 & 0 \\ 0 & 0 & -14.344 & 0 & 0.552 & 0 \\ 0 & 0 & 0 & 1 & 0 & 0 \\ 0 & 0 & 56.419 & 0 & -0.579 & 0 \\ 0 & 0 & 0 & 0 & 0 & 1 \\ 0 & 0 & -29.262 & 0 & -6.466 & 0\end{array}\right] \quad B_{1}=\left[\begin{array}{c}0 \\ 0.915 \\ 0 \\ -4.278 \\ 0 \\ 2.478\end{array}\right]$

$\dot{x}_{2}=A_{2} x_{2}+B_{2} u_{2}$

$A_{2}=\left[\begin{array}{ll}0 & 1 \\ 0 & 0\end{array}\right] \quad B_{2}=\left[\begin{array}{c}0 \\ 34.014\end{array}\right] u_{2}=C_{\delta}$

\section{Control strategy}

The TWSVPS can be decoupled into two subsystems, which are balance subsystem and deflection subsystem. So the parallel double fuzzy controller is designed to control this robot. The balance subsystem is a complex system of multi-input, multi-output and strong coupling. So the optimal fuzzy control algorithm based on information fusion was adopted in this research. At the same time the fuzzy control algorithm was also adopted in deflection subsystem. The control system block diagram is shown in Fig. 2 as the following.

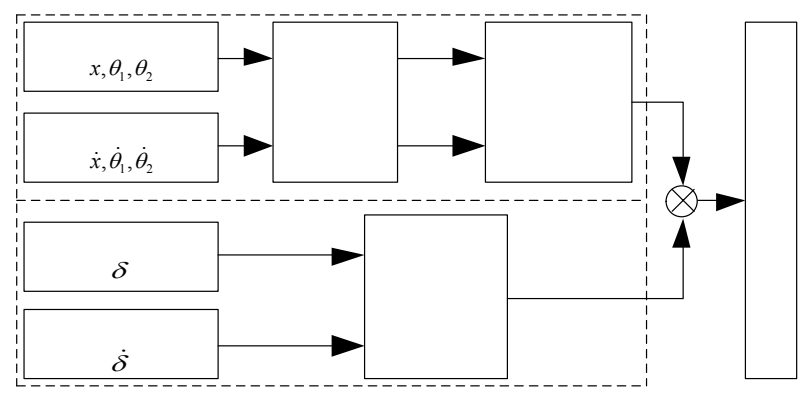

Figure 2 The control system block diagram

\subsection{Balance subsystem}

In order to simplify the design of fuzzy controller, the integrated error $\mathrm{E}$ was generated by fusing $x, \theta_{1}, \theta_{2}$ and the integrated error change EC was generated by fusing $\dot{x}, \dot{\theta}_{1}, \dot{\theta}_{2}$. The state feedback matrix $\boldsymbol{K}$ was given according to the linear quadratic optimal control theory. The $\boldsymbol{K}$ expression can be described as follows:

$\boldsymbol{K}=\left[K_{x}, K_{\theta_{1}}, K_{\theta_{2}}, K_{\dot{x}}, K_{\dot{\theta}_{1}}, K_{\dot{\theta}_{2}}\right]$

The quadratic performance index function can be described as follows:

$J=\int_{0}^{\infty}\left(X^{\mathrm{T}} \boldsymbol{Q} X+u^{\mathrm{T}} \boldsymbol{R} u\right) \mathrm{d} t$

where, $u=\boldsymbol{K} X^{\mathrm{T}}$.

The parameter choice of matrix $\boldsymbol{Q}$ and $\boldsymbol{R}$ has a great influence on dynamic performance of the closed-loop system. Weight matrices $\boldsymbol{Q}$ and $\boldsymbol{R}$ were usually determined by the researcher according to the subjective experience. If their decisions are different, the results are not identical, naturally. After many experiments, the matrix $\boldsymbol{Q}$ and $\boldsymbol{R}$ can be described as follows:

$Q=\left[\begin{array}{cccccc}1000 & 0 & 0 & 0 & 0 & 0 \\ 0 & 500 & 0 & 0 & 0 & 0 \\ 0 & 0 & 800 & 0 & 0 & 0 \\ 0 & 0 & 0 & 1 & 0 & 0 \\ 0 & 0 & 0 & 0 & 1 & 0 \\ 0 & 0 & 0 & 0 & 0 & 1\end{array}\right] ; R=1$

Calculated, the $\boldsymbol{K}$ expression can be described as follows:

$$
K=[31.6228,-62.9642,-7.0671,40.4851,-1.5130,-7.7851]
$$

The fusion function can be described as follows:

$F=\left[\begin{array}{cccccc}0.3859 & -0.7683 & -0.0862 & 0 & 0 & 0 \\ 0 & 0 & 0 & 0.4940 & -0.0815 & -0.0949\end{array}\right]$

The E and EC can be described as follows:

$\left[\begin{array}{c}E \\ E C\end{array}\right]=F X^{\mathrm{T}}$

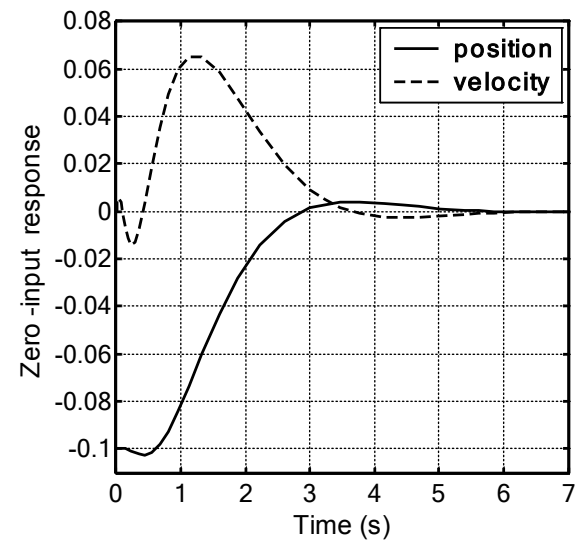

Figure 3 The input response of $x$ and $\dot{x}$ 
The two-dimensional fuzzy controller was designed and simulated in MATLAB, the input response wave forms of $x, \dot{x}, \theta_{1}, \dot{\theta}_{1}, \theta_{2}, \dot{\theta}_{2}$ are shown in Fig. 3, Fig. 4, Fig. 5.

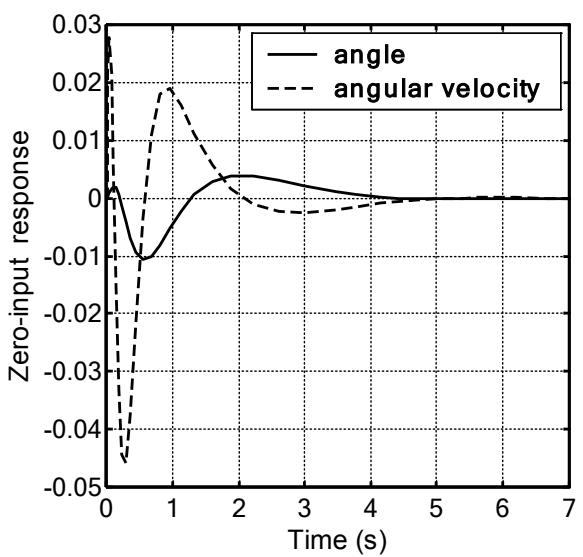

Figure 4 The input response of $\theta_{1}$ and $\dot{\theta}_{1}$

\subsection{Deflection subsystem}

The fuzzy controller is relatively simple for deflection subsystem, the error $\mathrm{E}$ was generated by $\delta$ and the error change EC was generated by $\dot{\delta}$. The twodimensional fuzzy controller was designed and simulated in MATLAB, the input response wave forms of $\delta$ and $\dot{\delta}$ are shown in Fig. 6.

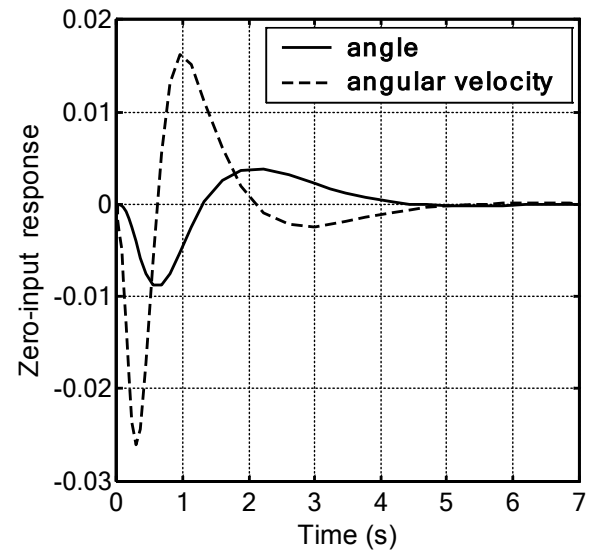

Figure 5 The input response of $\theta_{2}$ and $\dot{\theta}_{2}$

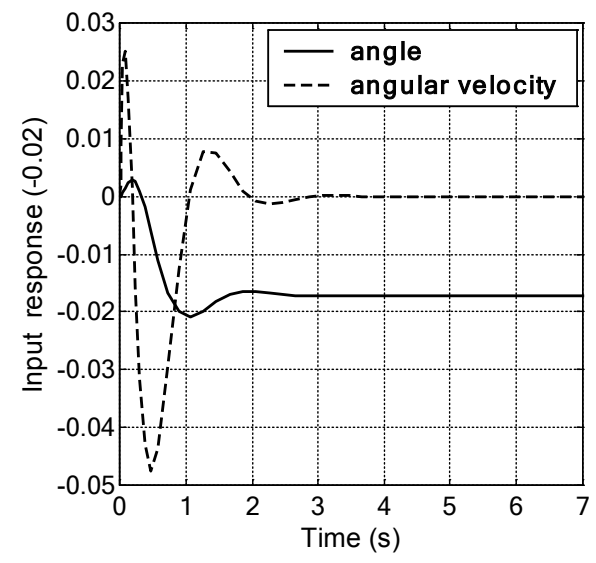

Figure 6 The input response of $\delta$ and $\dot{\delta}$

\section{Conclusion}

A new configuration of two-wheeled self-balancing vehicle-pendulum system has been presented in this research. The robot has the advantage of keeping the pendulum in the upright position in the process of movement. The dynamics model has been derived by Lagrangian equation and verified by simulating the system in MATLAB Simulink environment. The parallel double fuzzy controller based on information fusion technology was designed and applied to control the robot. Simulations of the TWSVPS moving on the smooth surfaces have been presented. The results show that the system was successfully stabilized and the control algorithm has great feasibility.

\section{Acknowledgment}

The authors acknowledge the support from Science and Technology Innovation Talents Special Foundation of Harbin (outstanding academic leaders) (No. 2014RFXXJ051).

\section{References}

[1] Jeong, S.; Takahashi, T. Wheeled inverted pendulum type assistant robot: design concept and mobile control. // Intelligent Service Robotics. 1, 4(2008), pp. 313-320. DOI: 10.1007/s11370-008-0024-5

[2] Nguyen Gia Minh Thao; Duong Hoai Nghia; Nguyen Huu Phuc. A PID Backstepping Controller for Two-Wheeled Self-Balancing Robot. // International Forum on Strategic Technology (IFOST), 2010

[3] Yufeng Zhuang; Zeyan Hu; Yi Yao. Two-Wheeled Selfbalancing Robot Dynamic Model and Controller Design. // Proceeding of the $11^{\text {th }}$ World Congress on Intelligent Control and Automation Shenyang, China, June 29 - July 4 2014.

[4] Azimi, M.; Koofigar, R. Model Predictive Control for a Two Wheeled Self Balancing Robot. // Proceeding of the RSI/ISM International Conference on Robotics and Mechatronics, Tehran, Iran, February 2013. DOI: 10.1109/icrom.2013.6510097

[5] Goher, K.; Ahmad, S.; Tokhi, M. O. A new configuration of two wheeled vehicles: Towards a more workspace and motion flexibility. // Proceedings of $4^{\text {th }}$ Annual IEEE conference on Intelligent Systems, San Diego, CA, USA, 58 April 2010. DOI: 10.1109/systems.2010.5482350

[6] Almeshal, A.; Goher, K.; Tokhi, M. Modelling of TwoWheeled Robotic Wheelchair With Moving Payload. // Proceedings of the $14^{\text {th }}$ International Conference on Climbing and Walking Robots and the Support Technologies for Mobile Machines (CLAWAR 2011), 2011. DOI: 10.1142/9789814374286_0085

[7] Almeshal, A.; Goher, K.; Tokhi, M. A new configuration of a two-wheeled double inverted pendulum-like robotic vehicle with movable payload on an inclined plane. // Proceedings of the First International Conference on Innovative Engineering Systems (ICIES), pp. 97-102, 2012. DOI:

[8] Al-Hadithi, B.; Barragan, A.; Andujar, J. Fuzzy Optimal Control for Double Inverted Pendulum. // Proceedings of the 7th IEEE Conference on Industrial Electronics and Applications (ICIEA), pp. 1-5, 2012. DOI: 10.1109/iciea.2012.6360687

[9] Sharma, B.; Tyagi, B. LQR-Based TS-Fuzzy Logic Controller Design for Inverted Pendulum-Coupled Cart System. // Systems Thinking Approach for Social Problems 
Lecture Notes in Electrical Engineering. 327, (2015), pp.

207-219. DOI: 10.1007/978-81-322-2141-8_18

\section{Authors' addresses}

\section{Qingwen Qian}

Corresponding author

Robotics \& its Engineering Research Center,

Harbin University of Science and Technology,

52 Xuefu Street, Nangang district,

Harbin, Heilongjiang Province, 150080, China

College of Mechanical and Electrical Engineering, Huangshan University,

39 Xihai Street, Tunxi district,

Huangshan, Anhui Province, 245041, China

wazz_5200@163.com

\section{Junfeng $W u$}

College of Automation,

Harbin University of Science and Technology,

52 Xuefu Street, Nangang district,

Harbin, Heilongjiang Province, 150080, China

\section{Zhe Wang}

College of Mechanical and Electrical Engineering, Huangshan University,

39 Xihai Street, Tunxi district,

Huangshan, Anhui Province, 245041, China

wz@hsu.edu.cn 